\title{
COMPARISON OF NAIL-PLATE FIXATION AND ENDER'S NAILING FOR INTERTROCHANTERIC FRACTURES
}

\author{
GRAHAM HALL, D. A. P. AINSCOW \\ From the Bath and Wessex Orthopaedic Hospital, Royal United Hospital, Bath
}

\begin{abstract}
Two comparable groups of patients with fractures of the trochanteric region of the femur were studied. One hundred and sixty-five fractures had been fixed with conventional nail-plates and 132 with Ender's nails.

Ender's nails gave superior results in the treatment of trochanteric fractures. The operation was quicker and less traumatic than that using conventional nail-plates and both the mortality rate and the time in hospital were reduced. More patients in the group with Ender's nails who were initially independent returned to an independent existence.
\end{abstract}

Fractures of the trochanteric region of the femur are common in orthopaedic practice. They can be managed satisfactorily by conservative means (Horn and Wang 1964), but most orthopaedic surgeons use internal fixation to allow early mobilisation.

This study was performed to assess the use of the Ender's nails in the management of trochanteric fractures. The patients were allocated to groups according to their medical condition before operation and their degree of social independence. This enabled a comparison of the different treatments in the two groups. We also classified the type of fracture with reference to stability (Evans 1949), since unstable fractures have consistently proved the most difficult to manage (Dimon and Hughston 1967).

\section{CLINICAL MATERIAL AND METHODS}

A total of 297 patients with fractures of the trochanteric region of the femur, who were treated by internal fixation at the Bath and Wessex Orthopaedic Hospital between January 1976 and December 1978 have been reviewed. The first 165 patients ( 29 men, 136 women) were treated by using a conventional nail-plate device of the fixed-angle Jewett design (36 patients) or the two-part nail and plate design of the McKee or McLaughlin types (129 patients). The subsequent 132 consecutive patients ( 22 men, 110 women) were treated by Ender's method (Kuderna, Böhler and Collon 1976).

The average ages of the two populations were similar. For the group with nail-plates the average was 78 years (range 40-98 years) and for the group with Ender's nails it was 76 years (range 56-94 years).

At the time of admission the patients were assessed for the presence of intercurrent illness and their social environment was classified into three types: independent-when the patient lived

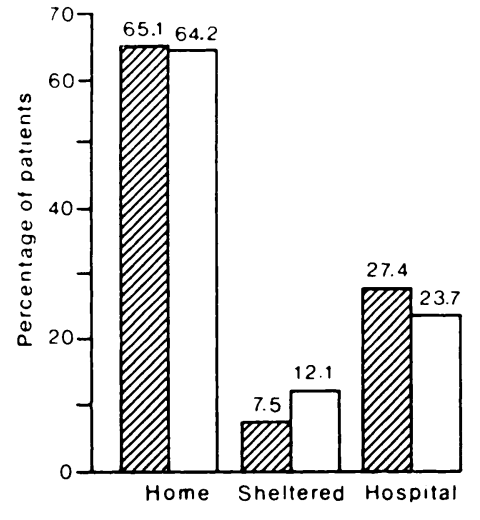

Fig. 1

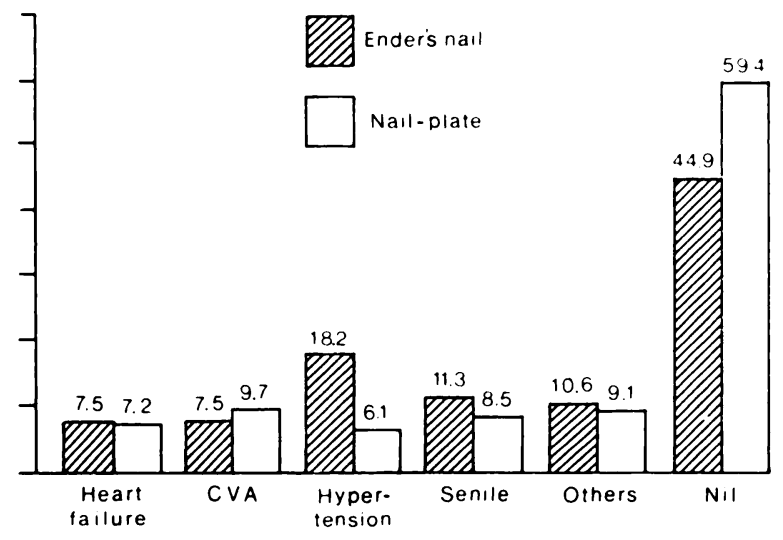

Fig. 2

Figure 1-Histogram to show the environment of the patients before fracture. Figure 2-Histogram to show the type of intercurrent medical condition of the patients before operation.

G. Hall, FRCS. Senior Orthopaedic Registrar, The Bath and Wessex Orthopaedic Hospital, Royal United Hospital, Combe Park, Bath BA1 3NG, England.

D. A. P. Ainscow, FRCS. Senior Orthopaedic Registrar, Southampton General Hospital, Shirley, Southampton SO9 4XY, England. Requests for reprints should be sent to Mr D. A. P. Ainscow.

(1) 1981 British Editorial Society of Bone and Joint Surgery 0301-620X/81/00120024\$2.00 
without assistance from others; sheltered - when the patient received substantial assistance with daily activities either from relatives or from social agencies; hospitalised-when the patient resided in an institution.

The social environment and the intercurrent medical condition before fracture were comparable in each of the two groups (Figs 1 and $2)$. The fractures were classified as basal, intertrochanteric or subtrochanteric and an assessment was made of the stability of the fracture. An unstable fracture possessed three or more main fragments or had comminution of the posterior or medial cortices. Comminution

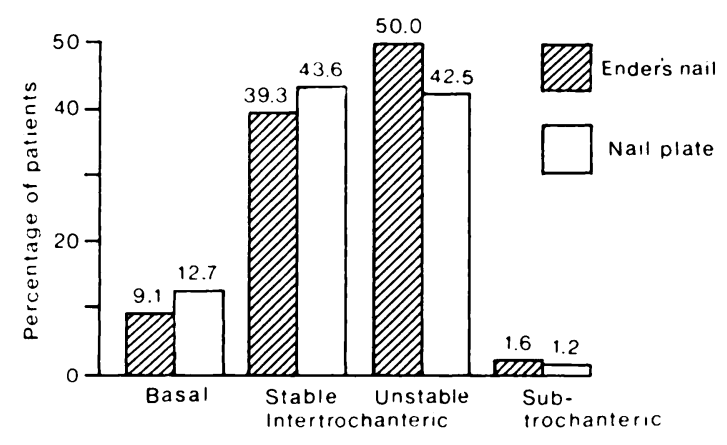

Fig. 3

Histogram to show the classification of the fractures before operation.

at these sites makes a fracture unstable even if anatomical reduction can be achieved (Dimon and Hughston 1967). The distribution of the fracture types was similar in each group (Fig. 3).

Closed reduction of the fracture was performed under general or regional anaesthesia with the patient on a traction table. The insertion of the fixation device was monitored using an image intensifier. The nail-plates were inserted using the standard lateral approach, whereas the Ender's nails were inserted via the medial femoral epicondyle.
Open reduction of the fracture was not performed. The total time for the operation, including positioning of the patient on the table and reduction of the fracture was recorded. The loss of blood at operation was estimated and the type of anaesthetic employed noted.

The incidence of complications and the mortality rate within the first three months after the operation were recorded for both types of fixation. The progress of the surviving patients was followed at least until the fracture united. The patients were examined for the presence of any disability, deformity or complaint but in eight patients this follow-up was not satisfactory. The progress of the fracture and the effect of fixation were analysed. Failure of the fixation was recorded if the patient was no longer mobile because of instability at the fracture site. Two types of failure of fixation were noted-mechanical failure of the implant caused by bending or breaking of the nail-plate (Fig. 4) and failure of the device to maintain fixation caused by Ender's nails backing-out of the femur (Figs 5 and 6) or the Trifin nail cutting-out of the neck of the femur. The time taken for union of the fracture and the final neck-shaft angle were measured with the aid of radiographs.

\section{RESULTS}

Operation. The average time for the group with Ender's nails was 39 minutes, which was substantially less than the 61 minutes for the group with nail-plates. The average blood loss was 120 millilitres in the Ender's nail procedure, which again was less than that for the nail-plate procedure with an average loss of 455 millilitres. However, it was usually necessary to transfuse patients in both groups with two units of blood, during the operation or immediately afterwards to prevent clinical anaemia.

General anaesthesia was used in 82 patients (62 per cent) treated with Ender's nails and in 122 patients ( 74

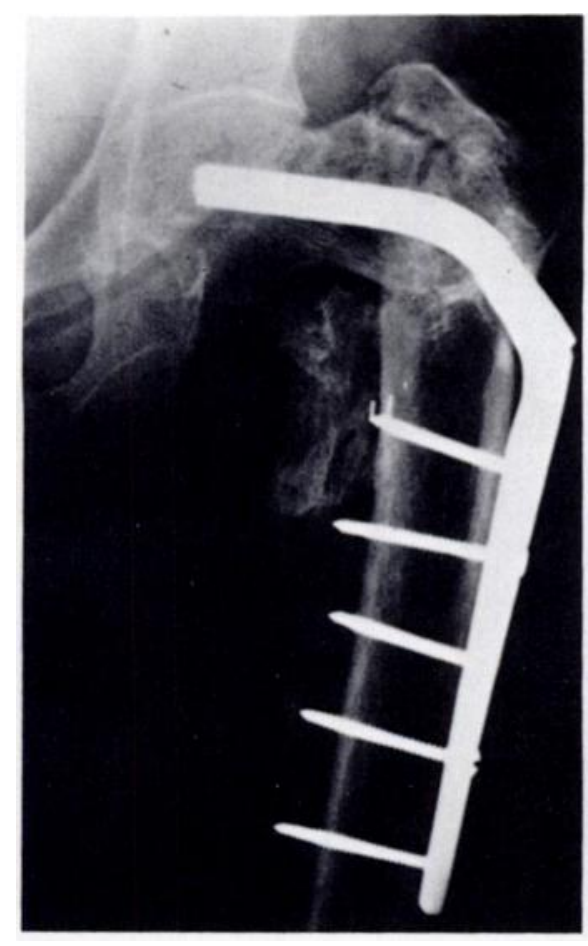

Fig. 4

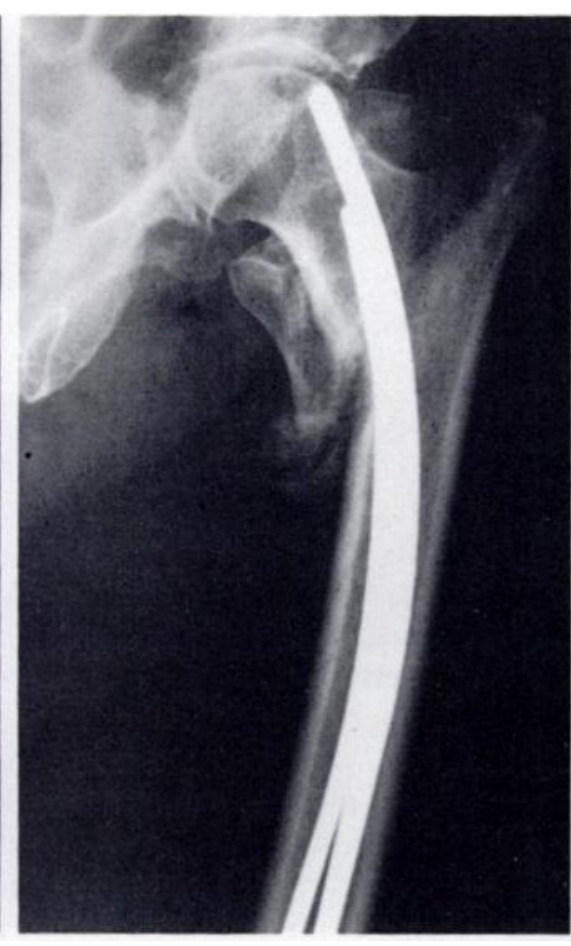

Fig. 5

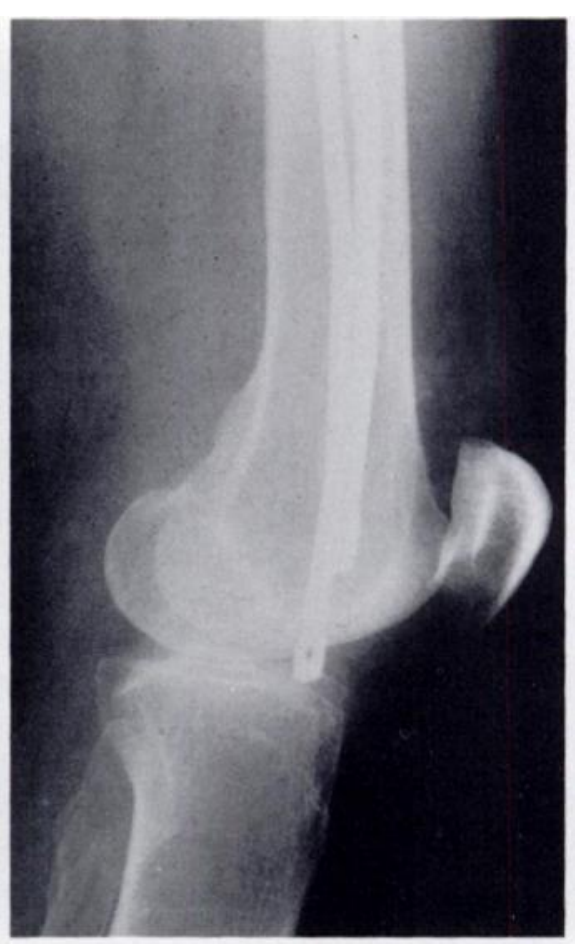

Fig. 6

Figure 4-Fixation failure caused by the bent and broken Jewett nail-plate implant. Figure 5-Fixation failure where backing-out of an Ender's nail has failed to maintain fixation in the top half of the left femur. Figure 6-Lower half of the left femur showing fixation failure with Ender's nail. 
per cent) of the patients with nail-plates. Regional anaesthesia was used in all the other patients. The only complication during the operation was a supracondylar fracture of the femur produced whilst inserting the Ender's nails. This was treated by circlage wiring and the application of a cast-brace which allowed mobilisation. Complications after operation. These were surprisingly few considering the age and medical condition of the patients.

The incidence, in particular the incidence of clinical deep-vein thrombosis requiring treatment and of wound infection, was less in the group with Ender's nails. (Fig. 7).

Mortality. In the group with Ender's nails the mortality at three months was 13 per cent, compared with 20 per patient as soon as possible. By the third day the patients with Ender's nails were bearing full weight -an event which was often delayed for two weeks in those with nail-plates.

Rehabilitation. The average time in hospital was 25 days for the patients with Ender's nails and $\mathbf{4 0}$ days for the group with nail-plates. Treatment with Ender's nails enabled 71 per cent of the patients who were initially independent to return home to an independent existence (Fig. 10), whereas the figure for the patients with nail-plates was only 56 per cent. Fixation with nail-plates seemed to offer some benefit to the small number of patients admitted from sheltered accommodation since a larger number returned to their place of origin and few died (Fig. 11). The results for patients

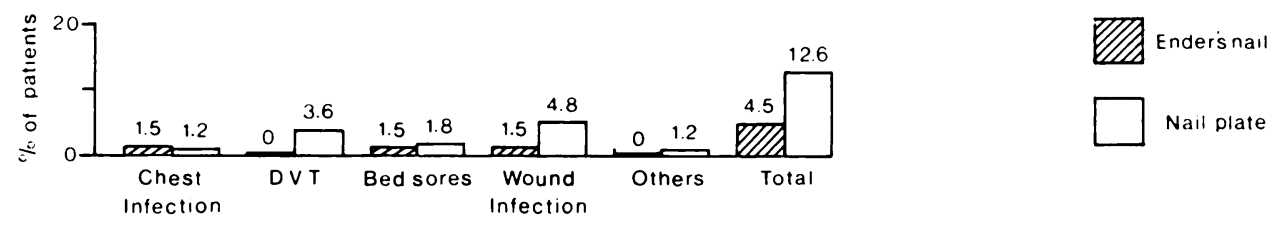

Fig. 7

Histogram to show the type of complications found after operation.

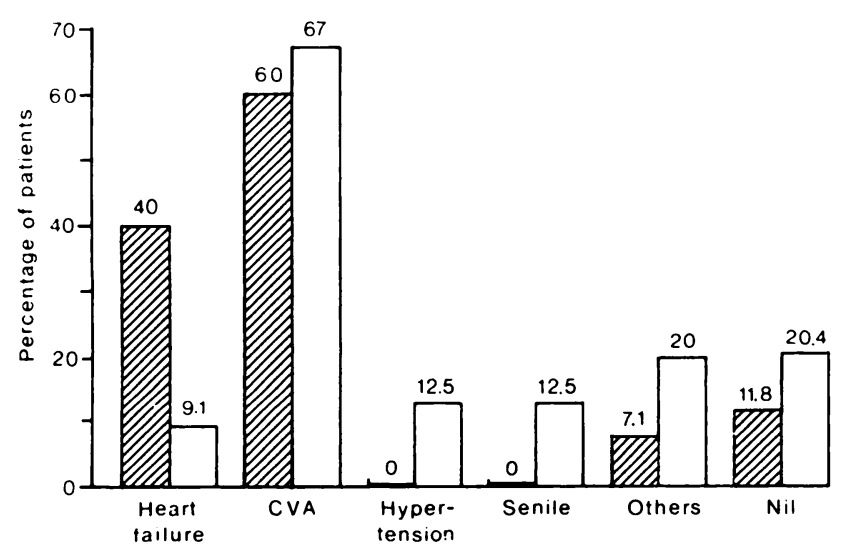

Fig. 8

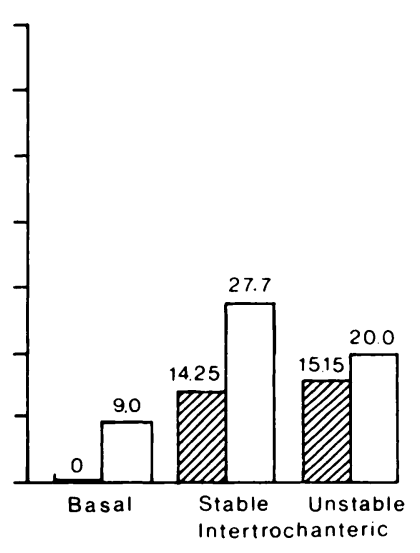

Fig. 9

Mortality as a percentage of patients in the different clinical groups. Figure 8-Mortality related to intercurrent medical condition. Figure 9-Mortality related to type of fracture.

cent for the group with nail-plates $(0.5>P>0.3)$. In patients with intercurrent cerebrovascular lesions, mortality was high with either form of treatment (Fig. 8). Amongst patients with heart failure, the mortality was 40 per cent in the group with Ender's nails, but only nine per cent in the group with nail-plates. Of the patients who had no intercurrent medical illness, 12 per cent of those treated with Ender's nails and 20 per cent of those with nail-plates were dead within three months.

The stability of the fracture had little effect on the mortality in those patients treated with Ender's nails (Fig. 9). Surprisingly, the highest mortality rate in the group with nail-plates occurred in the patient with stable fractures. Fixation using Ender's nails reduced the mortality rate in each type of fracture.

Mobilisation. An attempt was made to mobilise every admitted from hospital were similar in both groups. Approximately 60 per cent of the patients returned to hospital accommodation and the remainder died (Fig. 12).

Deformity. Three types of deformity occurred: varus deformity, shortening, and lateral rotation deformity. Varus deformity occurred more frequently in the group with nail-plates (Fig. 13); an angle of less than 130 degrees between the femoral neck and the shaft occurred in 23 per cent of the group compared to only six per cent of the group with Ender's nails. The most severe cases of shortening, greater than three centimetres, occurred in 13.5 per cent of the group with nail-plates, but there was no shortening of more than three centimetres in the patients with Ender's nails (Fig. 14). Lateral rotation was most common in the group with 
Ender's nails and 12 per cent had a rotational deformity of more than 20 degrees. However, very few patients complained of this lateral rotation deformity which does not hinder mobilisation. Lateral rotation tended to occur when the nails did not have a good grip on the proximal fragment and when the medullary cavity was wide. In younger patients this deformity may be cosmetically unacceptable.

Fixation failures. Fixation failure occurred when the patient was no longer satisfactorily mobile. In the group with nail-plates, there were nine cases of failure. Two fixation. These nails were removed. None of these six patients died.

Time to union. There were no cases of non-union in either group and the time for radiographical union was similar in both groups (Ender's nails 10.1 weeks, nail-plates 11.8 weeks).

\section{DISCUSSION}

Fractures of the trochanteric region are common and in the elderly often lead to loss of independence for the patient. This burden of dependent patients for hospitals
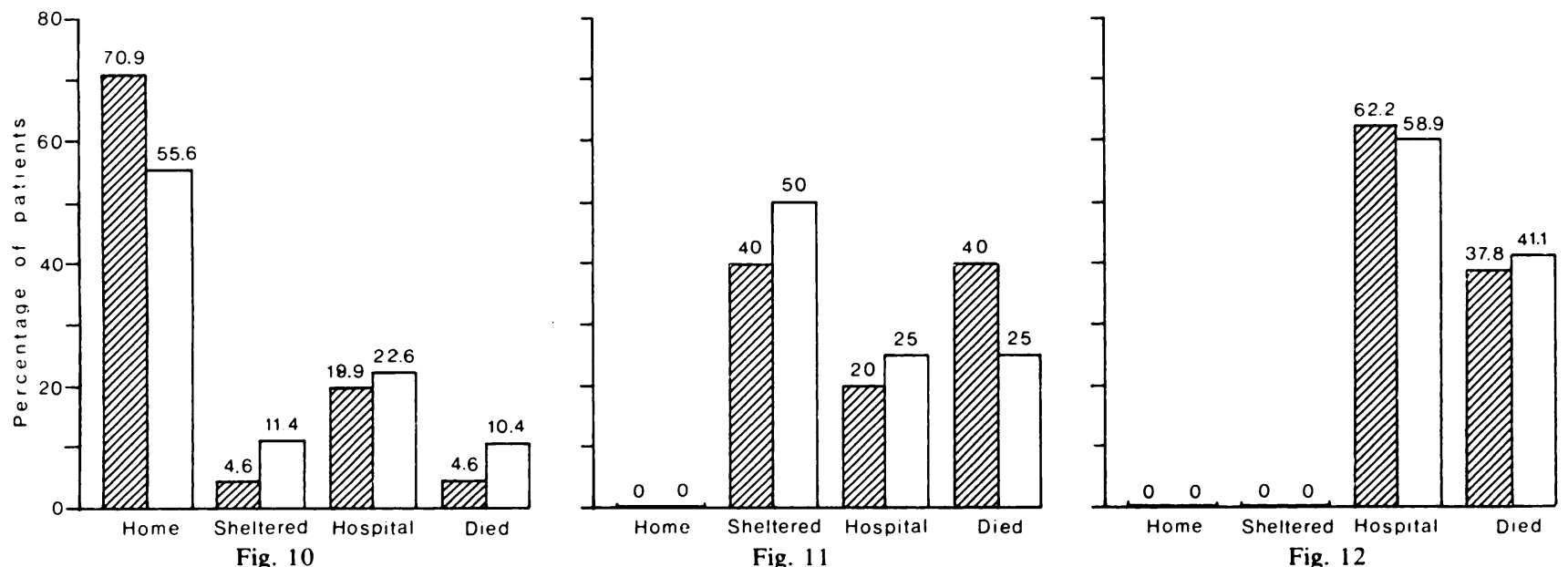

Effect of fixation on the ability of patients to return to their initial environment. Figure 10-Outcome for patients admitted from home. Figure 11 -Outcome for patients admitted from sheltered accommodation. Figure 12-Outcome for patients admitted from hospital.

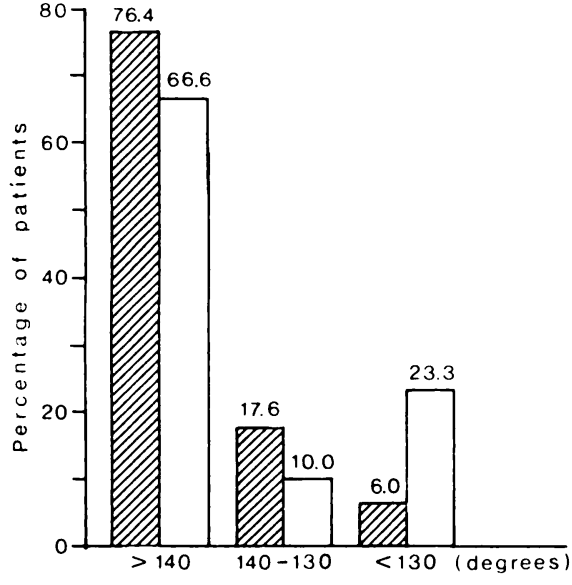

Fig. 13

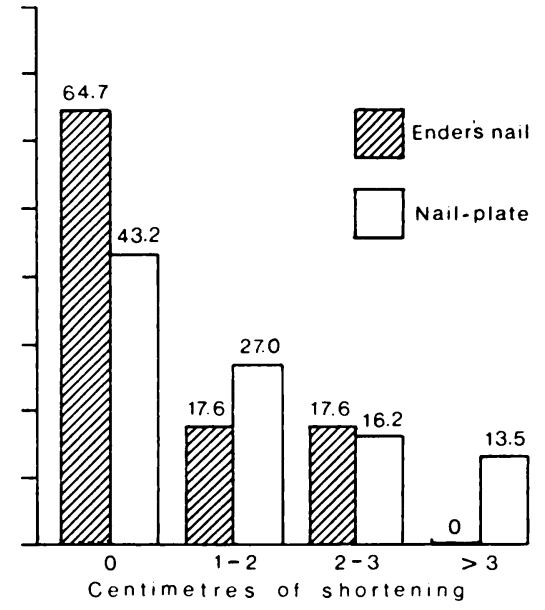

Fig. 14
Figure 13-Histogram to show the final angle between the femoral neck and the shaft in patients with varus deformity. Figure 14Histogram to show the amount of shortening in patients after operation. were caused by implant failure and seven by cutting-out. No benefit was conferred in this respect by using fixed-angle nail-plates of the Jewett design. Reoperation was performed on three of these nine patients and two patients in this group died. The Ender's nails implant failed to maintain reduction due to backing-out in three cases. In each of these cases, the nails were either repositioned or replaced with the addition of an extra nail. Three other nails backed-out and became subcutaneous at the knee but without compromising and social services will increase with an ageing population (Yellowlees 1978). The patients who make the best recovery after these injuries are those who return to their normal daily activities as rapidly as possible. Unrestricted weight-bearing on the fracture after operation is a great asset in such recovery.

With conventional fixation using nail-plates a comparatively large proportion of the unstable trochanteric fractures will redisplace and prevent further mobilisation of the patient (Kølind Sørensen 1975). 
Numerous innovations on the basic nail-plate design have been made in an attempt to reduce this incidence of fixation failure. The telescopic nail (Pugh 1955) and the more recent compression-screw device allow impaction to occur at the fracture site without the implant cutting out of the head or neck of the femur. Very strong implants have been designed to prevent failure (Holt 1963). Displacement osteotomy at the time of fixation to stabilise the fracture has also been advocated (Harrington and Johnston 1973).

The technique using Ender's nails is a different approach to the problem. Here the fracture is fixed in a position of relative valgus due to the shape of the nails and this position is maintained until union has occurred (see Fig. 13). This reduces the shearing stresses across the fracture site and increases the compression forces (Collado, Vila and Beltran 1973). Impaction takes place at the fracture site and the nails tend to move distally as this occurs. However, the fixation remains satisfactory during this movement since the length of the nail in the proximal fragment is constant. In the early cases, we found that the movement caused some nails to become subcutaneous at the knee, so we modified our technique to leave the distal ends of the nails within the medullary cavity which allows backing-out to occur without the nails becoming prominent at the knee.

The Ender's nails are closer to the weight-bearing axis of the femur and run along the lines of force within the femur. This reduces the bending moment of the implant (Corzatt and Bosch 1978) compared to the nail-plate device and is the reason for the absence of implant failure in the group with Ender's nails. Patients with Ender's nails spent less time in hospital and those who were initially fit had a reduced rate of mortality and a greater return to independent existence than in the patients with nail-plates. There are several explanations for these improvements. The stress of the operation, indicated by the time taken for the operation and the blood loss, is less for Ender's technique and patients recover from the operation more quickly. There were also fewer complications after the operation in the group with Ender's nails. This finding confirms previous reports by Wynne Jones et al. (1977). However, the most important factor is the ability to take full weight through the femur once it has been fixed, even in the unstable fractures. This allows rehabilitation to proceed as rapidly as possible. In unfit patients there was no advantage with Ender's nails and both types of fixation gave the same results.

In conclusion fixation with Ender's nails allows immediate mobilisation without restriction of weightbearing after operation. Rehabilitation is therefore more rapid than in the group with nail-plates. This reduces the time spent in hospital, and enables a greater number of patients to return to their previous state of independence.

We are grateful to the staff of the Medical Records Department, Royal United Hospital for their help in tracing the patients in this review and Miss L. Wolstenholme for help in the preparation of the manuscript. We would also like to thank the Consultant Orthopaedic Surgeons of the Bath and Wessex Orthopaedic Hospital for their enthusiasm and encouragement given to this study.

\section{REFERENCES}

Collado F, Vila J, Beltran JE. Condylo-cephalic nail fixation for trochanteric fracture of the femur.J Bone Joint Surg [Br] 1973;55-B:774-9. Corzatt RD, Bosch AV. Internal fixation by the Ender method. JAMA 1978;240:1366.

Dimon JH, Hughston JC. Unstable intertrochanteric fractures of the hip. J Bone Joint Surg [Am] 1967;49-A:440-50.

Evans EM. The treatment of trochanteric fractures of the femur. J Bone Joint Surg [Br] 1949;31-B:190-203.

Harrington KD, Johnston JO. The management of comminuted unstable intertrochanteric fractures. J Bone Joint Surg [Am] 1973; 55-A: $1367-76$.

Holt EP, Jr. Hip fractures in the trochanteric region: treatment with a strong nail and early weight-bearing. J Bone Joint Surg [Am] 1963;45-A:687-705.

Horn JS, Wang YC. The mechanism, traumatic anatomy, and non-operative treatment of intertrochanteric fracture of the femur. Br J Surg 1964;51:574-80.

Kolind Soresen V. Comminuted intertrochanteric fracture of the femoral neck. Acta Orthop Scand 1975;46:651-3.

Kuderna H, Böhler N, Collon DJ. Treatment of intertrochanteric and subtrochanteric fractures of the hip by the Ender method.J Bone Joint Surg $[A m]$ 1976;58-A:604-11.

Pugh WL. A self-adjusting nail-plate for fractures about the hip joint. J Bone Joint Surg [Am] 1955;37-A:1085-93.

Wynn Jones C, Morris J, Hirschowitz D, Hart GM, Shea J, Arden GP. A comparison of the treatment of trochanteric fractures of the femur by internal fixation with a nail plate and the Ender technique. Injury 1977;9:35-42.

Yellowlees Sir H. The National Health Service-thirty years on. Health Trends 1978;10:45-8. 